\section{Compreensões sobre a importância do Ensino de Artes pela escrita de cartas cirandeiras}

\author{
Understandings about the importance of Arts \\ Teaching in the writing of cirandeiras letters
}

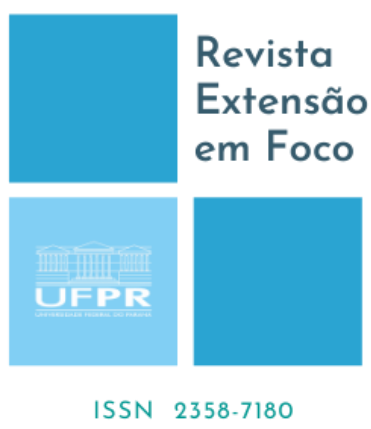

ISSN $2358-7180$

\author{
Diana Paula Salomão de Freitas ${ }^{1}$
}

\begin{abstract}
RESUMO
Apresenta-se uma carta escrita para professores(as) em formação acadêmico-profissional, participantes do projeto de extensão "Cirandar". Pela escrita de cartas cirandeiras quis compreender a importância do Ensino de Artes pela experimentação de situações práticas e reflexivas com Artes Visuais, Música, Teatro e Dança, para a construção de saberes capazes de subsidiar a ação docente de licenciandas(os) de Pedagogia. Promovido pela Universidade Federal do Rio Grande, o Cirandar tem se configurado como espaço de escrita, leitura e diálogo na formação de professores e, em 2020, por ter sido totalmente online, contou com a participação de professores(as) de diferentes cidades do Brasil. Nas cirandas, rodas de estudo, do projeto, professores(as), pela escrita de cartas, aprendem sobre um tema da sua escolha, referente a um assunto ou desafio pedagógico que desejam compreender. Este texto é a integração das quatro cartas produzidas no âmbito do projeto, nas quais busquei mostrar como cheguei ao cirandar e no objeto de estudo escolhido; como o contexto da pandemia e interlocuções teóricas contribuíram para esta escolha e seus desdobramentos. Num processo de escrita, rodas de conversa virtuais, leitura e reescrita das cartas, aprendi que ensinar artes desde a educação infantil é essencial, pois, a arte dá concretude ao sentir humano, desenvolvendo canais de relacionamento e afetividade, despertando consciência para novos modos de sensibilidade, fazendo Nosso Ser refletir por inteiro. Pela relevância da arte para o processo de formação integral humana, finalizo com apontamentos sobre a próxima investigação-ação a ser realizada no Cirandar, em 2021.

Palavras-chave: Formação acadêmico-profissional. Escrita de cartas. Ensino de artes. Formação integral.
\end{abstract}

\title{
ABSTRACT
}

A letter written to teachers in academic and professional training, participants of the extension project "Cirandar", is presented. By writing cirandeiras letters wanted to understand the importance of Arts Teaching by experimenting with practical and reflective situations with Visual Arts, Music, Theater and Dance, for the construction of knowledge capable of supporting the teaching action of pedagogy licensees. Promoted by the Universidade Federal do Rio Grande, Cirandar has been configured as a space for writing, reading and dialogue in teacher training and, in 2020 , because it was totally online, had the participation of teachers from different cities in Brazil. In the cirandas of the project, teachers, by writing letters, learn about a theme of their choice, referring to a subject or pedagogical challenge that they wish to understand. This text is the integration of the four letters produced within the scope of the project, in which I sought to show how I got to the cirandar and the chosen object of study; how the context of the pandemic and theoretical dialogues contributed to this choice and its consequences. In a process of writing, virtual conversation wheels, reading and rewriting of letters, I learned that teaching arts from early childhood education is essential, because art gives concreteness to human feeling, developing channels of relationship and affection, awakening awareness to new modes of sensitivity, making Our Being reflect in its entirety. Due to the relevance of art to the process of integral human formation, I conclude with notes on the next action investigation to be carried out at Cirandar in 2021.

Keywords: Academic and professional training. Letterwriting. Art teaching. Integral training

${ }^{1}$ Doutora em Educação em Ciências: Química da Vida e Saúde. Docente Adjunta na Faculdade de Educação da Universidade Federal de Pelotas (UFPel), Pelotas, RS, Brasil. E-mail: diana.freitas@ufpel.edu.br. Orcid: https://orcid.org/0000-0001-6944-2219 
Prezado/a colega professor/a,

Começo esta carta compartilhando com você trecho de uma entrevista feita por Eric Nepomuceno (2017) à poeta portuguesa, Matilde Campilho, que assim colocou:

"Eu lembro, uma vez eu era criança eu estava em Londres, e fui dar uma volta sozinha. Estava em família e falei: "não, hoje eu vou dar uma volta sozinha". E fui de mochila sozinha, sozinha pelos museus. E eu lembro um dia de entrar num museu e tinha uma sala imensa e com uma pintura imensa que eu, como criança que era, não fazia a menor ideia do que era aquilo. E quando eu entrei na sala, realmente, os meus joelhos fraquejaram um pouquinho. E eu fiquei encostada na mochila e depois na parede, olhando aquilo durante, meia hora, três quartos de hora, não sei. Efoi uma bofetada de beleza e de espanto! E fui embora e levei aquilo. E lembro-me que cheguei na minha família, um pouquinho depois e falei: "Eu vi uma coisa..." E os olhos brilhavam, meu pai sempre conta que os olhos brilhavam. E eles perguntaram, como bons adultos: "mas o que era?" E eu falei: "Não sei, mas era incrivel..." Então, mesmo criança, eu acho que naqueles cinco minutos, dez, teve uma função de salvação, quase. Durou aquele tempo só. Acho que a arte faz isso, salva momentos.

É engraçado que anos mais tarde eu estava na faculdade. Já conhecia alguns artistas e um dia estava fazendo um trabalho sobre o Polock e abri a um livro e apareceu aquela pintura inteira no livro. E eu voltei 20 para trás e falei: "Caramba, eras tu! Estavas aqui sempre!" E acho que essa é a função da arte, de fazer fraquejar os joelhos, um pouquinho, quando for preciso. De fazer tirar atenção da dor, em alguns momentos, $e$, outras vezes, levar atenção para dor, que eu acho que é necessário também. Muitas vezes andamos distraídos demais. Então acho que a arte cumpre esta função, de chamar".

Este trecho antecipa a você, colega, minha intenção com esta carta. Escrever para você, num processo de externalizar meu pensamento, entendê-lo e redefini-lo, no digitar das palavras. Relendo e refletindo se é isso mesmo que quero escrever. Tomando consciência de aspectos que ainda eram confusos ou mesmo desconhecidos por mim. A Trans-formação pela escrita, faz isso: leva a uma tomada de consciência que oportuniza um dar-se conta e, ao ser refinada, também um comunicar.

Isto, de se transformar pela escrita, transformando também quem lê, é um modo de ensinar-aprender que é realizado por um grupo de professores da Universidade Federal do Rio Grande (FURG). Em específico, desde 2012 este grupo, coordenado pela 
professora Maria do Carmo Galiazzi, vem realizando processos de formação de professores(as) como este, do qual estamos participando agora, em 2020/2021.

Escolhe-se um tema da nossa sala de aula sobre o qual pretendemos melhor compreender e, pela escrita de sucessivas cartas, previamente orientada pela coordenadora do projeto, dialogamos e reescrevemos em roda de estudos - este ano virtuais - realizada com outros(as) professores(as), de diferentes cidades do Brasil.

Bueno, mas o que tem a ver a transcrição da entrevista e o tema desta carta? Começo contando que, em 2020, após a redistribuição por permuta para outra Instituição Federal de Ensino, sou agraciada por trabalhar na formação de licenciandos(as), pelo meio fundamental para educarmos nossa sensibilidade, nossas emoções e nossas relações: a Arte.

Em conversa com minha orientadora de mestrado e doutorado, a professora Maria do Carmo Galiazzi - que sempre nos impulsiona a querer aprender mais pela escrita busco compreender acerca da importância do Ensino de Artes pela experimentação de situações práticas e reflexivas com Artes Visuais, Música, Teatro e Dança, para a construção de saberes capazes de subsidiar a ação docente de licenciandas(os) de Pedagogia. Assim sendo, como o referido projeto de extensão Cirandar é um autêntico “espaço de escrita, leitura e diálogo na formação de professores", junto com outros(as) colegas, busquei ampliar estar compreensão, na escrita e reescrita desta carta.

Início contando que em aulas da Pós-Graduação lato sensu e no mestrado acadêmico em Ensino, na Universidade Federal do Pampa (UNIPAMPA), retomei o trabalho com a vertente estético-educativa da educação ambiental. Digo que retomei, pois este envolvimento com educação estética - dos sentidos e da sensibilidade - começou em 2008. Naquele ano, cursei uma disciplina de Educação estético-ambiental no mestrado e continuei estudado sobre está, também no doutorado. Então, desde 2014 tenho me desafiado a desenvolver aulas de/com Educação Estético-ambiental.

Em formação acadêmico-profissional, junto com outras duas colegas parceiras, fomos responsáveis por organizar estratégias de ensino aprendizagem com uso de textos e outros materiais, além da criação de experiências do sensível, com o intuito de enriquecer o nosso relacionamento emocional com o meio ambiente, pela construção de saberes e conhecimentos acerca da educação estética e ambiental, junto com mestrandos(as) de um Programa de Pós-graduação acadêmico em Ensino. Nossa 
compreensão pautou-se em estudos e percepções de que é sobre nossa base emocional, desenvolvida em relação à realidade que, fundamentalmente, desenvolvemos nossas atitudes, posturas e princípios com relação às pessoas, demais seres vivos, fenômenos e objetos. Para isso, a Arte é o meio fundamental.

Antes de mostrar a concepção de alguns(mas) estudiosos(as) que me ajudaram a compreender acerca da importância do Ensino de Artes pela experimentação de situações práticas e reflexivas com as quatro linguagens das artes - música, teatro, dança e artes visuais - para a construção de saberes capazes de subsidiar a ação docente de licenciandas(os) de Pedagogia, cabe ainda contextualizar que este anseio é decorrente de um desafio assumido com atividades de ensino remotas, desenvolvidas durante a pandemia do COVID-19.

No começo parecia que seriam alguns dias. Depois, os dias se converteram em semanas. Agora, março de 2021, já são doze meses com atividades remotas. No início a gente seguia fazendo o que estava pendente, de certo modo. Alguma escrita ou finalização de relatório para os quais faltava tempo para se envolver. Depois veio a novidade: a redistribuição da UNIPAMPA para Universidade Federal de Pelotas (UFPel) saiu e então, novos(as) colegas, novas componentes curriculares e novos projetos.

Entrei em exercício de modo remoto e, no mês de abril de 2020, comecei a participar das reuniões gerais da Faculdade de Educação $(\mathrm{FaE})$ da UFPel, quando se deliberou que, no período de calendário alternativo, os professores ofertariam projetos de ensino, pesquisa e extensão, ao invés de disciplinas.

Começou aí um movimento que considero uma inovação pedagógica, no sentido de pensar junto e criar coletivamente estratégias para enfrentarmos os desafios colocados para o ensino, pela Pandemia. Isso porque, os(as) colegas se comunicavam e buscavam por parcerias para planejar conjuntamente atividades e aprender ferramentas pedagógicas virtuais para desenvolve-las. Para estruturação e acontecimento dos projetos também convidamos colegas de outras instituições.

A reflexão sobre a importância do ensino de artes e suas relações com as experiências com educação estético-ambiental aconteceram em virtude de um projeto de ensino submetido em co-coordenação com um professor de Música, colega na FAE, denominado "A Arte na Educação Infantil e nos Anos Iniciais no Contexto de Distanciamento Social”. 
Com o referido projeto realizamos, quinzenalmente, sete Rodas de Diálogo Virtuais (RDVs), de junho a setembro de 2020, durante 12 semanas, enfatizando as diferentes linguagens da arte, bem como a formação estética. Para cada especificidade, realizamos uma live com cinco professoras e um professor convidados, que trabalharam com os seguintes focos, na Educação Infantil e nos anos iniciais do Ensino Fundamental: a) formação estética/cultural (professora da UNIRIO), b) artes visuais (professor da FURG) e c) música, teatro e dança (três professoras do Centro de Artes - da UFPel). No encontro final do projeto, os participantes, que eram discentes do curso de Pedagogia da UFPel, apresentaram performances, a partir de uma ou mais linguagens da arte. Além das lives, foram realizados fóruns de diálogo, a partir de cada temática abordada, além da escrita de Diário com as reflexões pessoais, avaliação e autoavaliação do projeto. Entre as RDVs foram lidos textos de fundamentação sobre cada uma das temáticas abordadas.

Em outubro de 2020, iniciou-se o semestre letivo com ensino remoto, quando ofertamos disciplinas. Desta vez, com o objetivo de "experienciar situações práticas e reflexivas no campo da formação estética e da arte (artes visuais, música, teatro e dança), construindo saberes capazes de subsidiar a ação docente na área", conforme indicamos no Plano de Ensino. Ofertamos para duas turmas de 20 acadêmicos(as) do sexto semestre de Licenciatura em Pedagogia, o componente curricular "Práticas Educativas VI".

Novamente em parceria com o mesmo colega da FAE que desenvolvi o projeto de ensino já mencionado, organizamos atividades assíncronas com fóruns (05), wikis (02), questionário (01), leitura deleite, produção de vídeo (01) e elaboração e apresentação de sequência didática, além de diário de avaliação e autoavaliação (01). Para trabalhar com 34 discentes matriculados, também realizamos 10 encontros síncronos e, durante 12 semanas abordamos os seguintes tópicos e atividades com focos, na Educação Infantil e nos anos iniciais do Ensino Fundamental: a) formação cultural e estética, a partir de uma experiência para desabrochar os sentidos dos(as) participantes e discussão de um texto; b) música, com apresentação e discussão sobre alguns elementos essenciais da linguagem musical e da musicalização; c) dança e teatro, abordando e discutindo os principais conceitos da inserção destas linguagens nos planejamentos da escolares, com a participação do Grupo Pequenices Arte e Educação e a elaboração de uma proposta de teatro; d) desenho, a partir da audição de uma música, com conversa sobre a experiência, problematizando os desenhos estereotipados, a partir de texto indicado e e) apresentação de uma sequência didática elaborada sobre duas linguagens das artes, a partir de aula e 
texto previamente discutidos. Dos 34 acadêmicos(as) matriculados(as), 29 concluíram o trabalho.

Trouxe estes aspectos do projeto de ensino e da disciplina ofertados porque estas experiências e os textos estudados relacionam-se com o que busco compreender pela escrita desta carta, a importância do Ensino de Artes pela experimentação de situações práticas e reflexivas com Artes Visuais, Música, Teatro e Dança, para a construção de saberes capazes de subsidiar a ação docente de licenciandas(os) de Pedagogia.

A figura a seguir foi apresentada no último encontro da Roda Cirandar URUPEL que, uma vez por mês e pela escrita e leitura de cartas, de setembro a dezembro, reuniu professores de Uruguaiana, Pelotas e São Gabriel para discutir as cartas escritas no processo de formação oportunizado pelo Cirandar, em 2020. Na figura trago imagens e indicação de autores(as) que conheci nas experiências mencionadas; autores(as) que dialogam sobre o ensino das quatro linguagens das artes (a música, o teatro, a dança e as artes visuais).

Ilustro que, em interlocução com estes(as) ou com autores(as) referenciados em seus textos, busquei compreender a importância do Ensino de Artes e fortalecer o argumento desenvolvido na carta, indicando o modo como caminharei a partir desta parte.

Figura 1 - Proposta de organização da Carta 3, compartilhada com colegas da Roda Cirandar URUPEL.

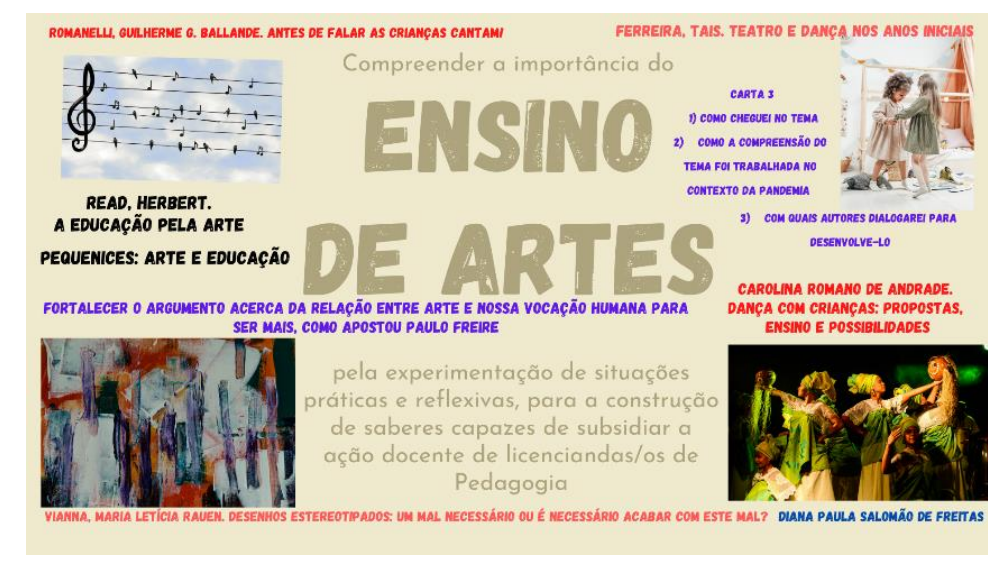

Fonte: Diana Salomão, 2020

Mas e o que os(as) autores(as) lidos e discutidos - ou aqueles(as) por eles(as) referenciados - no projeto e na disciplina me ensinam sobre a importância do ensino de artes? 
Aline de Paula, no seu trabalho de conclusão de curso (2002) traz definições de Arte a partir de Duarte Júnior (2004) e Scott McCloud (2004). Para Duarte Júnior (2004, p. 49) a arte "é uma tentativa de concretizar, em formas, o mundo dinâmico do 'sentir' humano", enquanto que Scott McCloud (2004) concebe a arte como "qualquer atividade humana que não se desenvolve a partir dos dois instintos básicos da nossa espécie: sobrevivência e reprodução" (MCCLOUD, 2004, p. 164).

Para Andrade "as aulas de arte poderiam ser um momento de conhecimento e desenvolvimento de inúmeros canais de relacionamento e afetividade entre professor e aluno" (2012, p.73). A arte desperta, assim, a consciência e novos modos de sensibilidade, capturando e até mesmo impulsionando mudanças. Nas palavras Martins; Picosque; Guerra (1998) trazidas por Andrade (2012, p.118) "Se a arte, como vimos, é, por si mesma, a experiência sensível em que nosso corpo perceptivo reflete; propor situações de aprendizagem em arte implica vibrar nesse corpo o assombro pelo mundo e o estranhamento diante daquilo que, amortecidos, com os sentidos embotados, já não vemos mais".

Para Joly e Severino (2016, p.20), o ensino da arte, pela educação musical "está presente no processo de desenvolvimento de pessoas, construindo e ativando memórias afetivas e culturais, criando identidades, permitindo que as pessoas, através da música, possam compreender o mundo e fazer parte dele". Numa prática social - como são os processos educativos - são desenvolvidas as relações das pessoas entre si - e com a natureza não humana - com a finalidade de "produzir bens, transmitir valores, significados "(2016, p.22). Com o propósito de produzir e valorizar culturas e assim, a diversidade.

Carolina Andrade, em seu livro "Dança com Crianças: propostas, ensino e possibilidades" (ANDRADE, 2018), atribui a arte de dançar o desenvolvimento da "possibilidade de se comunicar, projetar e refinar seu movimento por meio da dança" (ANDRADE, 2018, p.52). A comunicação aqui refere-se a um "vocabulário de movimento, a fim de que os movimentos aprendidos possam ser transformados em dança" (p.54). Um modo de criar, expressar e estabelecer relações com o mundo.

Garcez e Oliveira manifestam que, pelo ensino de artes, podemos promover experiências estética, capazes de provocar sensações. Nos dizeres das autoras: “As obras de arte expressam um pensamento, uma visão do mundo e provocam uma forma de inquietação no observador, uma sensação especial, uma vontade de contemplar, uma 
admiração emocionada ou uma comunicação com a sensibilidade do artista. A este conjunto de sensações chamamos de experiência estética" (2011, p.11).

Assim como as demais experiências promovidas por outras atividades de ensino, as experiências estéticas nem sempre serão agradáveis e prazerosas, levando, muitas vezes, àquele(a) que contempla a um estado de inquietação, reflexão e tristeza. Leva ainda a conhecer "a sensibilidade do artista, sua imaginação, seu intelecto, sua percepção especial da vida, mesmo quando apresenta aspectos negativos" (2011, p.11).

Andrade (2012) valoriza o ensino de artes enquanto um modo de estimular processos criativos que "se tecem com a multiplicidade de experiências e conhecimentos que habitam o sujeito, construídos a partir da convivência nos vários espaços sociais, tais como a escola" (2012, p.73). Processos criativos que acontecem com quem cria e com quem contempla, já que "Fazer arte não está relacionado única e exclusivamente a quem cria, compõe, inventa ou se expressa através de performances e exposições. Apreciar, observar, estudar, contemplar, visitar e compartilhar as manifestações artísticas também é "fazer arte" (PONICK, 2020).

Na apreciação de uma obra artística, conforme Andrade (2012) e Barbosa (1991) pode-se organizar pensamentos, sentimentos e aptidões para criar. A arte é um modo realmente potente de criação e reconhecimento de si, na medida em que "A criança em um determinado momento percebe que tudo que está depositado no papel partiu dela. Não lhe foi dado, foi inventado por ela mesma. Inaugura-se o terreno da criação". (DERDYK, 2003, p.64 apud SANTOS e FRATARI, 2011, p.7).

É neste sentido que Vianna (2012), coloca-se contrária aos estereótipos para o ensino de Artes. Em sua compreensão "Os desenhos estereotipados empobrecem a percepção e a imaginação da criança, inibem sua necessidade expressiva; embotam seus processos mentais, não permitem que desenvolvam naturalmente suas potencialidades. Estereotipar quer dizer então, simplificar, esquematizar, reduzir à expressão mais simples". (VIANNA, 2012, p.4). Por isso a professora coloca que "Não podemos aceitálos [os desenhos estereotipados] porque como educadores, acreditamos no poder de criatividade das pessoas, na individualidade de cada ser humano, acreditamos na necessidade vital que a criança tem de se expressar; porque somos contra a acomodação e desejamos a transformação. (VIANNA, 2012, p.4). 
Andrade (2012) traz ainda os ensinos de Eisner (1999), indicando a importância de ensinar artes contemplando: produção, crítica, história e estética da arte. Isto porque, segundo Eisner estas correspondem às quatro maneiras como nos relacionamos com a arte: “fazemos arte, vemos arte, entendemos o lugar da arte na cultura através dos tempos e fazemos julgamentos sobre suas qualidades" (EISNER, 1999, p.89 apud ANDRADE, 2012, p.79).

Santos e Fratari (2011) indicam ainda que, na educação infantil, a arte "possibilita que a criança amplie seu conhecimento, suas habilidades e a descoberta de suas potencialidades". A arte pode levar a expressar seus sentimentos, medos e frustrações, ampliando as relações com o mundo de forma espontânea. Expressando-se de diversas formas e com o uso de distintos materiais e repertórios, "A arte transforma e possibilita novos caminhos na vida da criança. Valorizar as produções infantis é valorizar o ser humano em seu desenvolvimento" $(2011$, p.3).

Com o objetivo maior de não apenas levar a conhecer grandes autores e renomadas obras ensinar artes possibilita que "a criança conheça tempos e lugares diferentes podendo falar dos seus sonhos, de sua cultura, de sua realidade, esperança e desesperança de seu modo singular de expressar por intermédio da arte" (Santos e Fratari,2011, p.4). A arte favorece a liberdade de expressão, desenvolve conhecimentos e habilidades pelas mais diferentes linguagens, contribuindo para a formação mais integral humana. Mais integral, pois, pela nossa vocação humana de Ser Mais, como colocou Paulo Freire, ao longo das experiências de vida, pela nossa humana incompletude, buscamos e temos capacidade para Ser mais infinitos e mais plenos.

Em síntese, caro colega, com os estudos que realizei no âmbito do Cirandar, aprendi que, ensinar artes desde a educação infantil é essencial! A arte dá concretude ao sentir humano, desenvolvendo canais de relacionamento e afetividade. A arte desperta consciência para novos modos de sensibilidade, fazendo Nosso Ser refletir por inteiro; por todas as partes do nosso corpo.

A arte potencializa o desenvolvimento das infinitas capacidades humanas. Ativa memórias afetivas, permitindo conhecer e nos sentir parte do mundo. Através de expressões artísticas visuais, musicais, teatrais e rítmicas, valores e culturas são transmitidos e a diversidade é assim admirada e estimada. 
A arte permite que artista e espectador se expressem e se comuniquem, também por inteiro. Experimentando diferentes materiais. A arte leva aquele que cria, aquele que contempla e a própria obra a se relacionarem. A arte inquieta, choca, emociona, espanta, extasia, tirando-nos do embotamento e desanestesiando, assim como também pode entorpecer. Nesse sentido, já que nos relacionamos de diferentes modos com arte, seja fazendo, seja admirando, seja deliberando sobre seus atributos e reconhecendo-a a partir de seus lugares, tempos e culturas é importante que seu ensino contemple: apreciação e crítica à produção, à história e à estética da arte.

A arte estimula processos criativos, levando além e mais além, criatura, criador e contemplador. Ajuda a reconhecer a si mesmo e organiza aptidões internas. Por isso, considero que o estudo e a elaboração das compreensões, elaboradas no contexto do Cirandar e aqui compartilhadas, ajudam a fortalecer o argumento de que temos mesmo a vocação para Ser Mais como apostou Paulo Freire. Infinitos e inacabados, a Arte é potente para o desenvolvimento das nossas inúmeras capacidades humanas.

O que precisamos é "Fazer mais artes!” e a escola, pela nossa ação docente é um lugar privilegiado para ensinar pela experimentação de situações práticas e reflexivas com Artes Visuais, Música, Teatro e Dança. Sendo assim, é impreterível que nos cursos de formação de professores (desde aqueles que atuarão com a educação infantil - com é a licenciatura em Pedagogia) sejam dialogados e construídos saberes capazes de subsidiar docentes para ensinarem as quatro linguagens das artes; cumprindo assim esta função de “chamar", de desestabilizar, de mobilizar, de fazer sentir, de fazer SER MAIS.

Sendo assim, pela relevância da arte para o processo de formação integral humana, assumo uma investigação-ação a ser realizada no Cirandar 2021. Quero investigar na minha prática docente, nas disciplinas que estão sob minha responsabilidade neste primeiro semestre letivo, de ensino remoto, como a Arte pode estar inserida nas disciplinas de Pré-Estágio e Teoria e Prática Pedagógica, ofertadas para licenciaturas em Geografia e Ciências Biológicas, respectivamente, e na disciplina ofertada no Mestrado Acadêmico em Ensino, Produção Cientifica e Revisão de Literatura, não como subsídio para, mas como conteúdo na trajetória do trabalho. Um desafio a ser assumido, pelos estudos e diálogos realizados no âmbito do projeto Cirandar, em 2021.

Diana Paula Salomão de Freitas.

Rio Grande, 24 de março de 2021. 


\section{REFERÊNCIAS}

ANDRADE, C. R. Dança com Crianças: propostas, ensino e possibilidades. 1.ed. Curitiba: Appris, 2018.

ANDRADE, E. B. F. A arte como um direito da criança: o papel do professor na construção de um mundo sensível. Revista Ibero-Americana De Estudos Em Educação, 7(1), 72-83, 2012. Disponível em: https://doi.org/10.21723/riaee.v7i1.5369. Acesso em: 10 jan. 2021.

BARBOSA, A. M. Inquietações e Mudanças no Ensino da Arte/Ana Mae Barbosa (org). In: Conceitos e terminologias. Aquecendo uma transforma-ação: atitudes e valores no ensino da arte. 2 ed. São Paulo: Cortez,2003

DUARTE JUNIOR, J. F. Por que Arte-educação? 15.ed. Campinas: Papirus Editora, 2004.

GARCEZ, L.; OLIVEIRA, J. Explicando a Arte Brasileira: uma iniciação para entender a apreciar as artes visuais. Nova Fronteira: Rio de Janeiro, 2011

JOLY, I. L. SEVERINO, N. B. Processos educativos e práticas sociais em música: um olhar para a educação humanizadora: Pesquisas em educação musical. Curitiba: CRV, 2016.

MATILDE CAMPILHO (Sangue Latino). Entrevistada: Campilho, M. Entrevistador: Nepomuceno, E. Nepomuceno Filmes. (26'01"). Transmitido ao vivo 17 abril de 2017 pelo Canal Brasil. Disponível em: https://www.youtube.com/watch?v=VldpHiRir4c. Acesso em: 20 mai. 2021.

MCCLOUD, S. Desvendando os Quadrinhos. São Paulo: M. Books, 2004

PAULA, A. I. M. Pontes que a Arte Constrói: reflexões, propostas e experiências poético-educacionais. 2018. Trabalho de Conclusão de Curso (Licenciatura em Artes Visuais). Escola de Música e Belas Artes do Paraná, Universidade Estadual do Paraná UNESPAR - Campus I, Curitiba, 2018.

PONICK. E. A Arte na Educação Infantil e nos Anos Iniciais no Contexto de Distanciamento Social. Projeto de Ensino. Disponível em: https://ava.ufpel.edu.br/pre/course/view.php?id=5019. Acesso em: 11 jan. 2021 
SALOMÃO DE FREITAS, D.P.; BRIZOLLA, F. MELLO, E. M; OLIVEIRA, N. R. M. Experiências didático-pedagógicas com educação estético-ambiental na formação acadêmico-profissional. 1. ed. Veranópolis: Diálogo Freiriano, 2020, p. 3337. Disponível em http://e-books.contato.site/ambiental. Acesso em: 20 mai. 2021.

SANTOS, A. M.; FRATARI, M. H. D. Artes Visuais na Educação Infantil. Artigo elaborado para a conclusão do curso Graduação em Pedagogia da Faculdade Católica de Uberlândia M-G. Pedagogia da Faculdade Católica de Uberlândia-MG. 2011/1. Disponível em: [https://silo.tips/download/artes-visuais-na-educaao-infantil-1palavras-chave-artes-visuais-educaao-infanti]. Acesso em: 09 jan. 2021.

VIAnNA, M. L. R. Desenhando Com Todos os Lados do Cérebro. Campo Largo: Ibpex, 2010.

Recebido em: 21 de maio de 2021.

Aceito em: 26 de maio de 2021. 